\title{
Extraction, Purification and Anti-Hyperlipidemic Activities of Total Flavonoids from Corn Silk
}

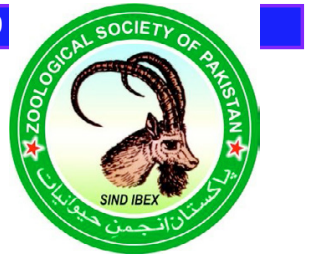

\author{
Jiandong Wu, Miao Ye and Zaigui Wang* \\ College of Life Sciences, Anhui Agriculture University, Anhui Hefei 230036, \\ P.R. China
}

Jiandong Wu and Miao Ye contributed equally.

\begin{abstract}
A B S T R A C T
In this study, some important parameters were optimized for effective extraction and purification of total flavonoids from corn silk, and the anti-hyperlipidemic activities was analyzed in rabbits by feeding experiment. Firstly, the high extraction yield $\left(5.32 \mathrm{mg} \cdot \mathrm{g}^{-1}\right)$ of total flavonoids were obtained under the optimal extraction conditions, which are $80^{\circ} \mathrm{C}$ for $3 \mathrm{~h}$ with corn silk over $60 \%$ ethanol ratio of $1: 30$. Then, the AB-8 resin was selected for the purification of flavonoids due to the higher static adsorption and adsorption capacity than other resins. The optimum conditions for purifying flavonoids as follows: for adsorption, sample concentration was $2.542 \mathrm{mg} \cdot \mathrm{mL}^{-1}, \mathrm{pH}$ was 3.7 , processing volume was $4 \mathrm{BV}$; flow rate was 2 $\mathrm{BV} \cdot \mathrm{h}^{-1}$; temperature was $25^{\circ} \mathrm{C}$. For desorption, elution solvent ethanol-water $(95 \%$, v/v) solution was 4.5 $\mathrm{BV}$; flow rate was $2.0 \mathrm{BV} \cdot \mathrm{h}^{-1}$. Flavonoids with content of $68.3 \%$ were obtained with a flavonoid recovery of $93.7 \%$. The results showed that AB-8 resin revealed a good ability to purify total flavonoids. Lastly, feeding experiments results indicated that flavonoids had significant anti-hyperlipidemic activities to rabbits by reducing the content of serum total cholesterol (TC), triglycerides (TG), and low-density lipoproteincholesterol (LDL-C) and increasing the concentration of high-density lipoprotein-cholesterol (HDL-C).
\end{abstract}

Article Information
Received 16 February 2017
Revised 12 April 2017
Accepted 29 May 2017
Available online 21 November 2017
Authors' Contribution
JW and ZW designed the study,
performed the experiments and
wrote the manuscript. MY and JW
interpreted the results.
Key words
Corn silk, Flavonoids, AB-8 resin,
Purification, Anti-hyperlipidemic
activities.

\section{INTRODUCTION}

$\mathrm{C}$ Corn silk (dried cut stigmata of maize female flowers, Zea mays L.) is a well-known functional food and traditional Chinese herbal medicine. It consists of various bioactive constituents which has significant influence on human health. Corn silk had a long history of application for therapeutic remedy, including the antioxidant activities (Liu et al., 2011), anti-diabetic activity on hyperglycemia rats (Zhao et al., 2012) and the inhibitory effect on melanin production (Choi et al., 2014). However, corn silk has been discarded as waste in most cases due to lack efficient method for extracting and purifying the bioactive constituents in China. Thus, how to explore an effective way for recycling the corn silk is a hotspot recently.

Flavonoids are important secondary metabolites widely exist in the plants. Some flavonoids or isoflavones were extracted from plants exhibited kinds of biological activities such as estrogenic, anti-oxidant activities, antiosteoporosis, anti-diabetes and anti-carcinogenic effects (Wan et al., 2014; Zhao et al., 2012; Zhang et al., 2007).Corn silk contains various compositions: proteins, vitamins, $\mathrm{Ca}$, $\mathrm{Mg}$ and Na salts, oils, steroids, alkaloids, saponins, tannins, polysaccharide and flavonoids (Ebrahimzadeh et al., 2008).

\footnotetext{
Corresponding author: wangzaigui2013@163.com 0030-9923/2017/0006-2173 \$9.00/0

Copyright 2017 Zoological Society of Pakistan
}

Flavonoids are one of the main constituents of corn silk and are considered to be an important active ingredient in corn silk. Previous studies showed that flavonoids from corn silk have many pharmacological effects, such as anti-oxidative (Liu et al., 2011) and anti-fatigue activity (Hu et al., 2010). However, little research about the antihyperlipidemic activities of corn silk was reported.

The preparative enrichment of active components from plant extracts is an important step in the manufacture of phytochemical-rich products. There are several methods, such as liquid-liquid extraction (Biazus et al., 2007), ion exchange (Smith and Evens, 1995) and expanded bed adsorption (Biazus et al., 2006), available in the literature for the enrichment and separation of active constituents. However, these methods are not particularly effective regarding reagents, energy consumption and labor intensiveness. Comparatively, macroporous resins become one of the most effective methods with purification process for the purification and recovery of plant secondary metabolites (Fu et al., 2006; Kim et al., 2007; Qin and Jin, 2014) due to high adsorption capacity with possible recovery of the adsorbed molecules, relatively low cost and simple procedure (Liu et al., 2004).

Therefore, the extraction and purification conditions of total flavonoids were firstly optimized in this paper. Then the AB- 8 resin was selected for the purification flavonoids due to the higher adsorption and desorption rate than other resin in the purification process. Through the purification of 
AB-8 resin, the total flavonoids concentration was notable improved compared to the crude flavonoids. Lastly, the anti-hyperlipidemic activity of flavonoids was determined by the rabbits feeding experiment.

\section{MATERIALS AND METHODS}

\section{Chemicals and materials}

Analytical-grade methanol, ethanol, hydrochloric acid, sodium hydroxide and aluminium trichloride were purchased from the Guoyao biotech company. Standard samples of rutin were supplied by the National Institute of Control of Pharmaceutical and Biological Products (China). The macroreticular resins (AB-8, ADS-8, NKA-2 and X-5) were purchased from Chemical Plant of Nankai University (Tianjin, China). Rabbits weighing 300-400 g were purchased from Experimental Animal Center, Anhui agricultural University, China. Corn silk was collected from the horticultural center of Anhui agricultural university (Hefei, China). Corn silk was dried for $24 \mathrm{~h}$ by using a hot air oven at $70^{\circ} \mathrm{C}$ and powdered and then was stored in a drying cabinet before the experiment.

\section{Sample preparation and analytical methods}

Extraction of flavonoids from corn silk was performed as following: the dried powder $(5 \mathrm{~g})$ was subjected to hot continuous extraction in Erlenmeyer flask using 50-65\% ethanol at the material ratio of the weight $(\mathrm{g})$ of corn silk to the volume of ethanol $(\mathrm{mL})$ of $1: 20$ to $1: 35$. The resulting mixture was heated at the temperature of $60-90^{\circ} \mathrm{C}$ for $1-4$ $\mathrm{h}$ and stirred constantly. Then the extract was filtrated by using the filter. The obtained filtrate was evaporated by using a rotary evaporator (RE-52A, Shanghai Yalong Co., Ltd., Shanghai, China) under vacuum at $60^{\circ} \mathrm{C}$ to get the crude flavonoids. The extraction solution was stored at $4^{\circ} \mathrm{C}$ until used.

The standard curve of flavonoids content was analyzed using rutin as the standard at $400 \mathrm{~nm}$, using an ultraviolet (UV) spectrophotometer, and the standard curve was obtained, $\mathrm{C}=0.03040 \mathrm{X}+0.00097$ with $\left(\mathrm{R}^{2}=\right.$ 0.99986). Here, $C$ is the concentration (in units of $\mathrm{mg} / \mathrm{L}$ ) of flavonoids in the solution and $\mathrm{A}$ is the absorbance of the solution. The UV-2300 spectrophotometer (Shanghai Tianmei Co., Ltd., Shanghai, China) was used and wavelength was set at $400 \mathrm{~nm}$.

\section{Preparation of resin}

Before use, the AB- 8 macroporous resin was soaked in $95 \%$ ethanol for $24 \mathrm{~h}$ and washed several times using the deionized water. Then the resins were placed into a 1.2-cm inner diameter (id) glass column, and $2 \mathrm{BV}$ (where $\mathrm{BV}$ represents the column bed volume) of $5 \% \mathrm{HCl}$ and the same quantity of $\mathrm{NaOH}(5 \%)$ were sequentially passed through the column at a flow rate of $2 \mathrm{BV} \cdot \mathrm{h}^{-1}$ to remove impurities. Finally, the column was washed with deionized water at the same flow rate until the effluent was chemically neutral.

\section{Static adsorption and desorption tests}

In the static adsorption experiment, $1 \mathrm{~g}$ of resin and $20 \mathrm{~mL}$ of crude flavonoids solution $\left(2.542 \mathrm{mg} \cdot \mathrm{mL}^{-1}\right)$ were introduced into an air-tight Erlenmeyer flask of $150 \mathrm{~mL}$ capacity, which was then shaken $\left(100 \mathrm{r} \cdot \mathrm{min}^{-1}\right)$ in a waterbath shaker at $25^{\circ} \mathrm{C}$ for $24 \mathrm{~h}$ to establish equilibrium. Then the concentration of flavonoids left in the solution was analyzed using spectrophotometer at $400 \mathrm{~nm}$ according to the standard curve.

The desorption process was conducted as follows: After adsorption equilibrium was reached, the resin was first washed by deionized water and then desorbed with $40 \mathrm{~mL} \mathrm{95 \%} \mathrm{ethanol} \mathrm{solution.} \mathrm{The} \mathrm{flask} \mathrm{was} \mathrm{shaken} \mathrm{(100}$ $\left.\mathrm{r} \cdot \mathrm{min}^{-1}\right)$ in a water-bath shaker at $25^{\circ} \mathrm{C}$ for $24 \mathrm{~h}$. Then the concentration of flavonoids left in the solution was analyzed using spectrophotometer at $400 \mathrm{~nm}$.

\section{Dynamic adsorption and desorption tests}

Dynamic adsorption and desorption experiments were carried out in a glass column $(1.2 \times 40 \mathrm{~cm})$ wet-packed with $4 \mathrm{~g}$ of the selected AB- 8 resin. The bed volume (BV) of resin was $20 \mathrm{~mL}$. The flow rate of sample $\left(1-4 \mathrm{BV} \cdot \mathrm{h}^{-}\right.$ $\left.{ }^{1}\right)$ through the glass column, sample concentration (1-3 $\left.\mathrm{mg} \cdot \mathrm{mL}^{-1}\right)$ and different $\mathrm{pH}$ values of crude flavonoids were optimized in the adsorption experiments at $25^{\circ} \mathrm{C}$. Then the sample solution in a reasonable $\mathrm{pH}$ was pumped through the glass column at optimized flow rate by a peristaltic pump (ZT60-600, Baoding Lange Constant Pump Co., Ltd., Hebei, China). After adsorption equilibrium at the optimized condition, the adsorbate-laden column was successively eluted by deionized water and $95 \%$ ethanol at prescribed flow rate. The concentrations of flavonoids in the effluents $(5 \mathrm{~mL} /$ tube collected) were determined by spectrophotometer analysis.

Calculation of adsorption capacity, ratios of adsorption and desorption and recovery yield

$$
\text { Adsorption capacity }(\mathrm{Q})=\mathrm{Q} \frac{\left(\mathrm{C}_{0}-\mathrm{C}_{\mathrm{e}}\right) \mathrm{V}_{0}}{\mathrm{~W}}
$$

Where, $\mathrm{Q}$ is adsorption capacity at adsorption equilibrium ( $\mathrm{mg} \cdot \mathrm{g}^{-1}$ resin), $\mathrm{C}_{0}$ and $\mathrm{C}_{\mathrm{e}}$ are the initial and equilibrium concentrations of corn silk in the solutions, respectively $\left(\mathrm{mg} \cdot \mathrm{mL}^{-1}\right), \mathrm{V}_{0}$ is the volume of the initial sample solution $(\mathrm{mL})$ and $\mathrm{W}$ is the weight of the dry resin $(\mathrm{g})$. 


$$
\text { Adsorption ratio }\left(\mathrm{E}_{1} \%\right)=\frac{\mathrm{C}_{0}-\mathrm{C}_{1}}{\mathrm{C}_{0}} \times 100 \%
$$

Where, $\mathrm{E}_{1}$ is the adsorption ratio $(\%), \mathrm{C}_{1}$ represents the concentration of the solute in the supernatant after $24 \mathrm{~h}$ $\left(\mathrm{mg} \cdot \mathrm{mL}^{-1}\right)$ and $\mathrm{C}_{0}$ is the same as above.

$$
\text { Desorption ratio }\left(E_{2} \%\right)=\frac{C_{2}}{C_{0}-C_{1}} \times 100 \%
$$

Where, $\mathrm{E}_{2}$ is the desorption ratio (\%), $\mathrm{C}_{2}$ is the concentration of flavonoids in the desorption solution $\left(\mathrm{mg} \cdot \mathrm{mL}^{-1}\right)$ and $\mathrm{C}_{0}$ and $\mathrm{C}_{1}$ are the same as above.

$$
\text { Recovery yield }(\mathrm{Y} \%)=\frac{\mathrm{C}_{2} \mathrm{~V}_{2}}{\left(\mathrm{C}_{0}-\mathrm{C}_{\mathrm{a}}\right) \mathrm{V}_{\mathrm{p}}} \times 100
$$

Where, $\mathrm{Y}$ is the recovery yield (\%), $\mathrm{C}_{\mathrm{a}}$ is the concentration of flavonoids in the effluent liquid $\left(\mathrm{mg} \cdot \mathrm{mL}^{-1}\right), \mathrm{V}_{\mathrm{p}}$ is the processing volume of the sample solution $(\mathrm{mL}), \mathrm{V}_{2}^{\mathrm{p}}$ is the volume of the desorption solution $(\mathrm{mL})$ and $\mathrm{C}_{0}$ and $\mathrm{C}_{2}$ are the same as above.

\section{Animals and grouping}

Rabbits weighing 300-400 g were purchased for the feeding experiment. Rabbits were housed in plastic cages under controlled condition and fed on well-balanced diet (20\% casein, $10 \%$ soybean oil, $5 \%$ cellulose, $4 \%$ mineral mix, $2 \%$ vitamin mix, $6 \%$ sucrose, and $53 \%$ cornstarch). Twenty rabbits were randomized into 2 groups (experiment group and control group) equally based on body weight and external characteristics after one week adoption. Rabbits of the experiment groups were fed on balanced diet supplemented with $0.2 \%$ of purified flavonoids and the control group were received the same volume of balanced diet for 21 consecutive days, respectively (Kim et al., 2009; Weggemans and Trautwein, 2003).

\section{Anti-hyperlipidemic activities}

After 21 days, Blood samples of experiment group and control group were collected through heart puncture, allowed to coagulate and centrifuged to obtain serum for biochemical analysis. Then the concentration of TC, TG, LDL-C and HDL-C in the blood from rabbits of experiment group and control group were determined according to procedure described by Allian et al. (1974), Fossati and Prencipe (1982) and Jing et al. (2010). The data were analyzed with SPSS 10.0 software.

\section{RESULTS AND DISCUSSION}

\section{Extraction of total flavonoids from corn silk}

The ethanolic method was wildly used for the extraction of total flavonoids from plants (Wan et al.,
2014; Li et al., 2011; Feng et al., 2012). In this processes, some important factors directly determine the extracting efficiency. So for maximizing the extraction yields of total flavonoids and minimizing the production cost, the different extraction conditions of total flavonoids from corn silk were analyzed. The yield of total flavonoids increased with increasing extraction time (up to about 3 h) and temperature (up to about $80^{\circ} \mathrm{C}$ ) (Fig. $\left.1 \mathrm{~A}, \mathrm{~B}\right)$, with extraction temperature being more significant (the yields increased about 1.5 folds from $70^{\circ} \mathrm{C}$ to $80^{\circ} \mathrm{C}$ ). Insufficient extraction duration yielded less flavonoids, and the yield can reached a maximum after 3-4 h of extraction (Fig. 1A). Furthermore, a higher extraction temperature of $80^{\circ} \mathrm{C}$ was preferred for maximizing the ratio of the yield of total flavonoids to the energy consumption (Fig. 1B). During extraction, the yield of total flavonoids from corn silk was also found to be associated with the material ratio of the weight of corn silk to the volume of ethanol (60\%). A moderate ratio of $1: 30\left(\mathrm{~g} \cdot \mathrm{mL}^{-1}\right)$ was preferred for its higher yield and lower cost requirement than the ratios of 1:25 and 1:35 (Fig. 1C). To reduce the cost, a relatively lower solvent, from $50 \%$ to $65 \%$, were tested in experiment. The results showed that $60 \%$ ethanol can obtain higher yields than other concentration (Fig. 1D). It was probably due to the similar polarity between the $60 \%$ ethanol and the flavonoids (Rostagno et al., 2003). Thus, 60\% ethanol was selected as the solvent for extraction. In summary, the optimum extraction conditions were determined to be $80^{\circ} \mathrm{C}$ for $3 \mathrm{~h}$ with corn silk over $60 \%$ ethanol ratio of $1: 30$ to achieve the best extraction of total flavonoids. Under the optimum extraction conditions, about $5.32 \mathrm{mg}$ of total flavonoids were separated from one gram of corn silk.

\section{Adsorption and desorption capacities, desorption ratio of resins}

Enrichment of active components from plant extraction is important step for the usage of active constituents. Due to its low cost, high efficiency and simple procedure, resin adsorption seems to be the most suitable method compare with the membrane filtration, ion exchange and expanded bed adsorption. Four macroporous resins with different properties (AB-8, ADS-8, NKA-2 and $\mathrm{X}-5$ ) were tested through static adsorption and adsorption capacity, ratios of adsorption and desorption were used to evaluate their adsorbent efficiency. As shown in Table I, the adsorption and desorption ratios of total flavonoids on AB-8 resins were significantly higher than those of other resins, this result was consistent with previous study $(\mathrm{Hu}$ et al., 2010; Zhao et al., 2011). The adsorption capacities of the total flavonoids on AB-8 resins was $20.52 \mathrm{mg} \cdot \mathrm{g}^{-1}$ dry resin with desorption ratio of $94.8 \%$. Therefore, the AB- 8 resin was selected for the purification experiments. 

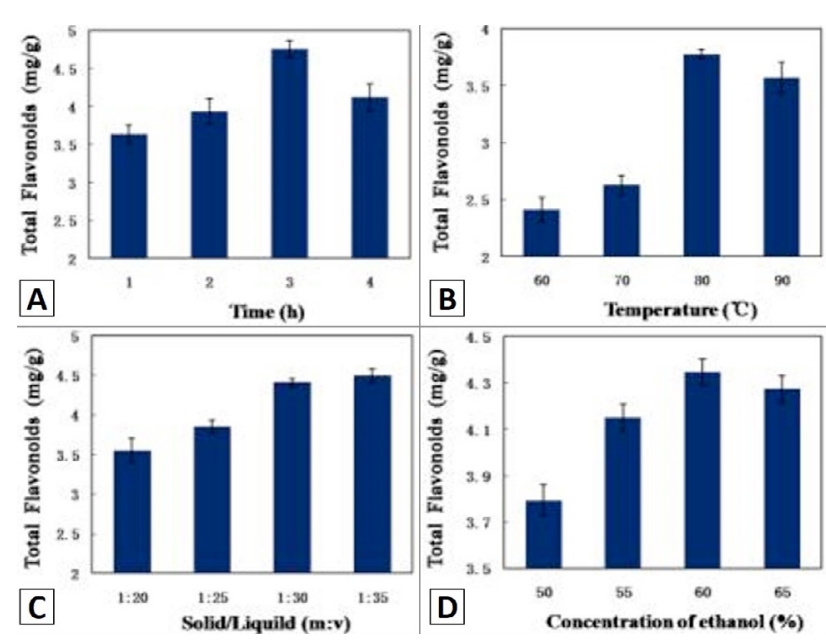

Fig. 1. Yield of total flavonoids from corn silk $(\mathrm{mg} / \mathrm{g})$ by extraction: A, for different durations with the material ratio (the weight of corn silk to the volume of $60 \%$ ethanol: $\mathrm{g} /$ $\mathrm{mL}$ ) of $1: 30$ at $80^{\circ} \mathrm{C} ; \mathrm{B}$, at different temperature with the material of $1: 30$ for $3 \mathrm{~h}$; $\mathrm{C}$, with different material ratio at $80^{\circ} \mathrm{C}$ for $3 \mathrm{~h}$; $\mathrm{D}$, for different ethanol concentration with material ratio of $1: 30$ for $3 \mathrm{~h}$ at $80^{\circ} \mathrm{C}$. Experiments were repeated at least three times with similar results.

Table I.- Adsorption capacities, adsorption and desorption ratios of different resins.

\begin{tabular}{llll}
\hline $\begin{array}{l}\text { Varieties of } \\
\text { resin }\end{array}$ & $\begin{array}{l}\text { Adsorption } \\
\text { capacity (mg/g) }\end{array}$ & $\begin{array}{l}\text { Adsorption } \\
\text { ratio (\%) }\end{array}$ & $\begin{array}{l}\text { Desorption } \\
\text { ratio (\%) }\end{array}$ \\
\hline AB-8 & 20.52 & 49.51 & 94.77 \\
ADS-8 & 15.86 & 38.17 & 81.12 \\
NKA-2 & 14.65 & 31.99 & 77.47 \\
X-5 & 10.26 & 14.82 & 75.41 \\
\hline
\end{tabular}

Optimization of adsorption and desorption parameters for total flavonoids

To obtain the highest enrichment of total flavonoids with $\mathrm{AB}-8$ resin, the effect of $\mathrm{pH}$ value of crude flavonoids, the flow rate, sample concentration and purification temperature on the adsorption rate were investigated in the flowing experiments. As shown in the Figure 2A, the highest adsorption capacity for the total flavonoids appeared at the $\mathrm{pH}$ values of 3.7 , and then decreased with the increase of $\mathrm{pH}$ value. These results suggested that hydrogen bonding is critical to the adsorption process on AB-8 resin. The affinity between solutes and solutions is changed due to the $\mathrm{pH}$ influence the extent of ionization of solutes (Zhao et al., 2011). Due to the dissociated of phenolic hydroxyl groups in the total flavonoids to $\mathrm{H}^{+}$and their corresponding anions at higher $\mathrm{pH}$ value, thus resulting in the adsorption capacity reducing. Sample solutions with different concentration of the total flavonoids (1-3 $\left.\mathrm{mg} \cdot \mathrm{mL}^{-1}\right)$ were also prepared for purification. As can be seen from Figure 2B, with the increasing of concentration from $1 \mathrm{mg} \cdot \mathrm{mL}^{-1}$ to $2.5 \mathrm{mg} \cdot \mathrm{mL}^{-1}$, the desorption capacity significantly increased. When the concentration is up to $2.5 \mathrm{mg} \cdot \mathrm{mL}^{-1}$, the adsorption rate is at its maximum. Over the $2.5 \mathrm{mg} \cdot \mathrm{mL}^{-1}$, the adsorption rate is decreasing.

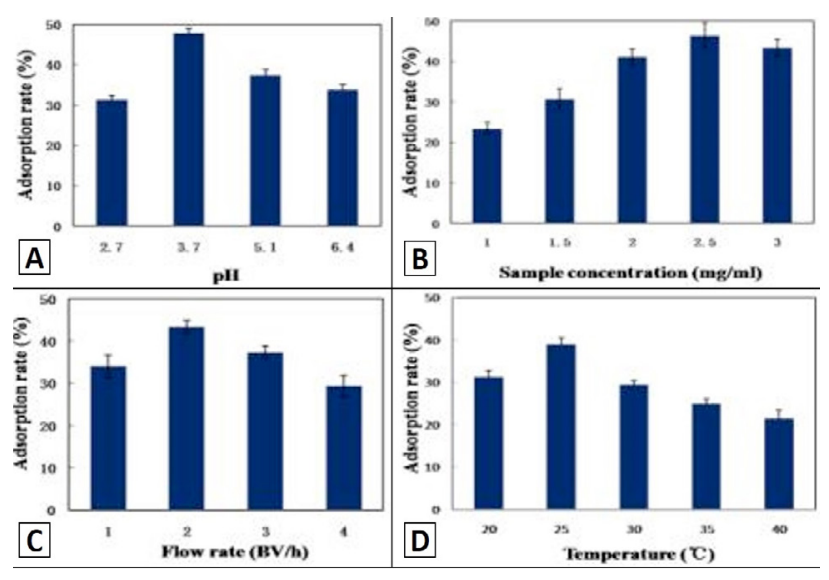

Fig. 2. The adsorption rate of macroporous resin AB- 8 by purification: $\mathrm{A}$, with different $\mathrm{pH}$ value of sample; $\mathrm{B}$, at different sample concentration $(\mathrm{mg} / \mathrm{mL})$; $\mathrm{C}$, for different flow rate $(\mathrm{BV} / \mathrm{h}) ; \mathrm{D}$, at different temperature $\left({ }^{\circ} \mathrm{C}\right)$. Experiments were repeated at least three times with similar results.

In addition, the effect of flow rate on dynamic adsorption capacity was tested. The results showed that the flow rate of $2 \mathrm{BV} \cdot \mathrm{h}^{-1}$ has larger adsorption capacity than flow rates of others (Fig. 2C). The reason for this is likely that the low flow rate was favorable to the diffusion in particle and liquid film of corn silk flavonoids molecules in the resin layer. Previous study showed that $25^{\circ} \mathrm{C}$ was the most suitable temperature for the adsorption of AB-8 resin (Wan et al., 2014), similar results were found in our experiments (Fig. 2D).

The proper desorption solution was chosen according to the polarity of resins and the flavonoids solubility in the desorption solution. The desorption rate was carried out with different concentrations ethanol solution at the flow rate of $2 \mathrm{BV} \cdot \mathrm{h}^{-1}$. At the $30 \%$ ethanol, the total flavonoids were hardly desorbed. When the ethanol concentration was over $30 \%$, the desorption rate increased sharply and reached $93.7 \%$ with the $95 \%$ ethanol (Fig. 3). Although the desorption rate with $100 \%$ ethanol was slightly higher than that with $95 \%$ ethanol, yet the $95 \%$ ethanol was selected for the later dynamic desorption curve analysis due to the lower cost. 


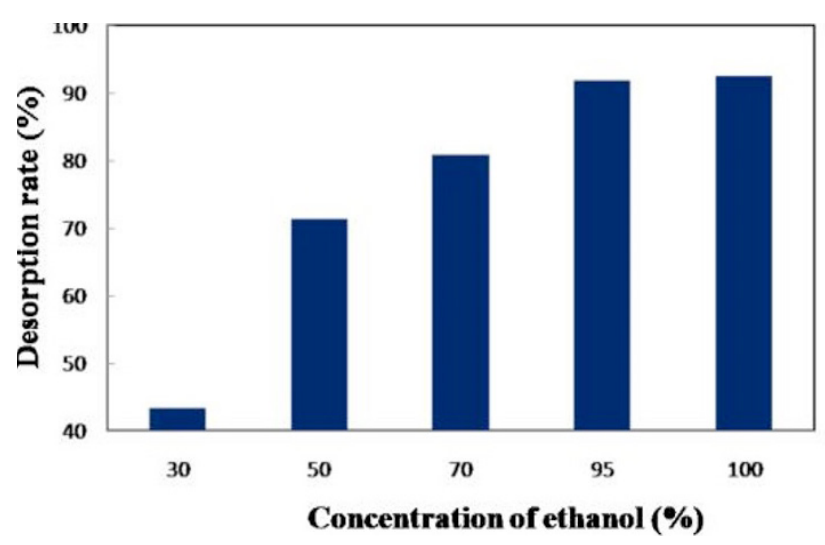

Fig. 3. Effect of different ethanol-water solutions on the desorption ratio of total flavonoids on $\mathrm{AB}-8$ resin.

Dynamic breakthrough and desorption curve on $A B-8$ resin

The solute leakage from the column at breakthrough point was due to the resin in the column approached to be saturated. The breakthrough point was be defined as $10 \%$ of the ratio of the exit to the inlet solution concentration (Hu et al., 2010). Therefore, construction of the leakage curve is important to calculate the quantity of resins, the processing volume of sample solution and the proper sample flow rate. The dynamic leakage curves on AB-8 resin were obtained according to the volume of effluent liquid and the tested constituents' concentration. As shown in Figure 4A, flavonoids in solution was almost completely adsorbed by the AB- 8 resin before 4 BV (breakthrough point), and then the concentration of flavonoids in leak solution increased rapidly until it reached a steady plateau in $7 \mathrm{BV}$. Therefore, the $4 \mathrm{BV}$ of sample solution on AB-8 resin was selected for dynamic adsorption experiments.

According to the results of breakthrough volume determined above, the $4 \mathrm{BV}$ sample solution was fed on the column packed with $4 \mathrm{~g}$ AB- 8 resin. After adsorption equilibrium the resin was first flushed with $4 \mathrm{BV}$ of distilled water for removing the high polar components in the crude extraction of corn silk, such as polysaccharides and amino acids. And then the adsorbent was eluted with $95 \%$ ethanol aqueous. The dynamic desorption curves on AB-8 resin were obtained based on the volume of effluent and the concentration of solute therein. The flow rate in this test was $2 \mathrm{BV} \cdot \mathrm{h}^{-1}$. As can be seen in Figure 4B, the concentration of flavonoids in elution solution was increasing with the increasing of the volume of elute, reaching a maximum value at $2 \mathrm{BV}$ and then decreased. Adsorption solution of 4.5 BV could completely desorbed flavonoids from AB-8 resin. In summary, the optimization of the desorption conditions: elution solvent ethanol-water $(95 \%, \mathrm{v} / \mathrm{v})$ solution was $4.5 \mathrm{BV}$; flow rate was $2 \mathrm{BVh}^{-1}$.
Flavonoids with content of $68.3 \%$ was obtained with a flavonoids recovery of $93.7 \%$ in the purification process.

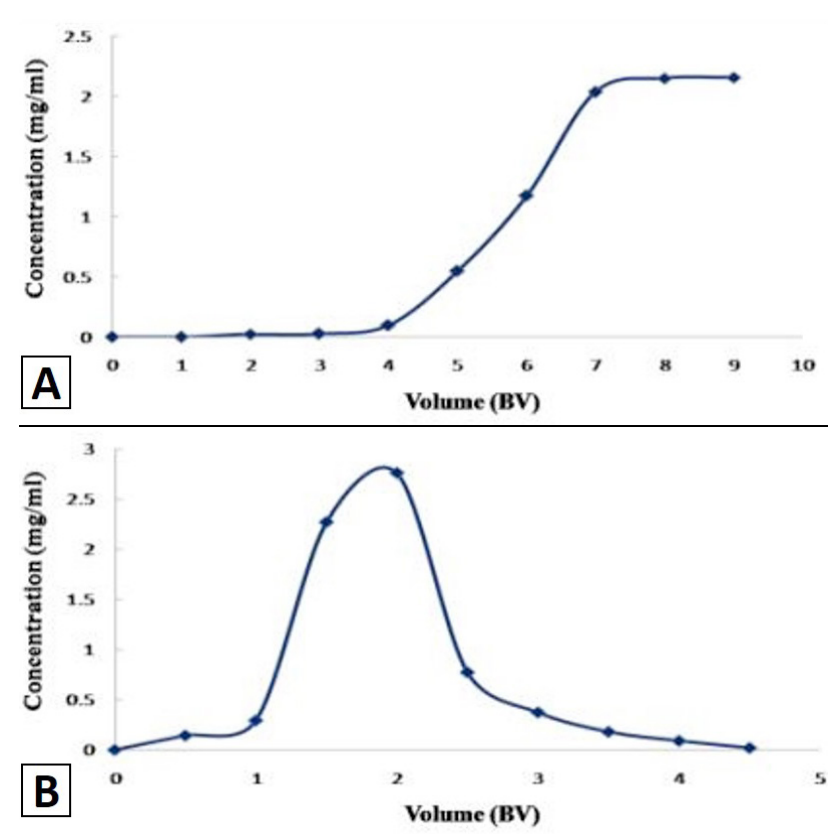

Fig. 4. Dynamic breakthrough (A) and dynamic adsorption (B) curves of total flavonoids on column packed with $\mathrm{AB}-8$ rein. Experimental condition: temperature, $25^{\circ} \mathrm{C}$; flow rate, $2 \mathrm{BV} / \mathrm{h}$; concentration of total flavonoids, $2.5 \mathrm{mg} / \mathrm{mL}$.

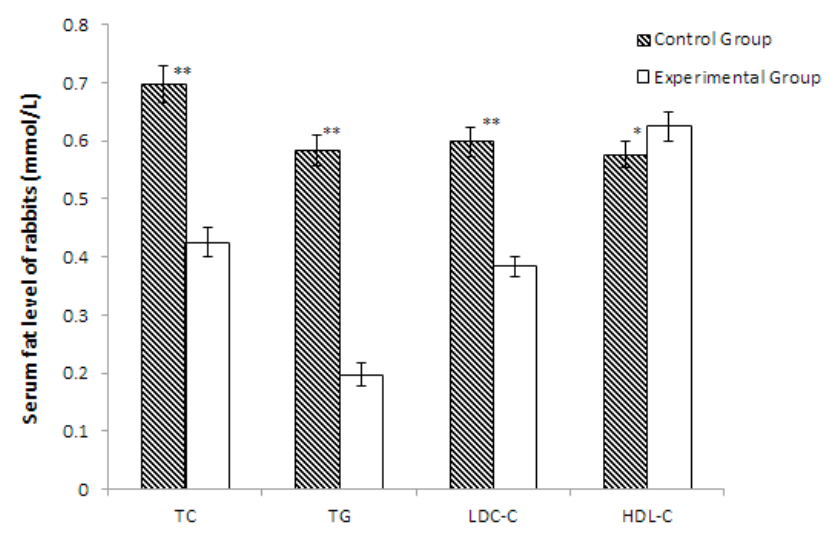

Fig. 5. Effects of total flavonoids on the serum flat level in rabbits. Data are expressed as mean $\pm \mathrm{SEM}$, each group contains ten mice $(\mathrm{n}=10), *, \mathrm{p}<0.05 ; * *, \mathrm{p}<0.01$. TC, total cholesterol; TG, triglycerides; LDL-C, low-density lipoprotein-cholesterol; HDL-C, high-density lipoproteincholesterol.

\section{Anti-hyperlipidemic activities}

The concentration of serum TC, TG, LDL-C and HDL-C were important parameters to serum lipids level (Bibi et al., 2016; Jung et al., 2014; Hamza et al., 2013; 
Jing et al., 2010). Weggemans and Trautwein (2003) also reported that flavonoids intake decreased LDL-C and increased HDL-C that may enhance removal of cholesterol from peripheral tissue to liver for catabolism and excretion. To determine the anti-hyperlipidemic activities of total flavonoids from corn silk to rabbits. The content of TC, TG, LDL-C and HDL-C of rabbit serum lipids from experiment group and control group were detected. As previous study, the content of TC, TG and LDL-C of experimental group rabbits had significantly reduction compared to control group after three weeks feeding (Fig. 5 ), and the decreasing rate were $60.9 \%, 194.2 \%$ and $64.9 \%$, respectively. However, the concentration of HDL-C in serum of feeding experimental group rabbits was higher than the control group. These results suggested that total flavonoids of corn silk have notable anti-hyperlipidemic activity.

\section{CONCLUSIONS}

In this study, the total flavonoids from the corn silk was extracted with higher content under the optimum extraction conditions were determined to be $80^{\circ} \mathrm{C}$ for $3 \mathrm{~h}$ with corn silk over $60 \%$ ethanol ratio of $1: 30$. The AB- 8 resin was selected for the purification of crude flavonoids because of the higher absorption and desorption rate. In this process, the impact factor of desorption capacity and desorption rate were optimized. The results were as follows: for adsorption, sample concentration was $2.542 \mathrm{mg} \cdot \mathrm{mL}^{-1}$, $\mathrm{pH}$ was 3.7, processing volume was $4 \mathrm{BV}$; flow rate was $2 \mathrm{BV} \cdot \mathrm{h}^{-1}$; temperature was $25^{\circ} \mathrm{C}$; for desorption, elution solvent ethanol-water $(95 \%, \mathrm{v} / \mathrm{v})$ solution was $4.5 \mathrm{BV}$; flow rate was $2.0 \mathrm{BV} \cdot \mathrm{h}^{-1}$; Flavonoids with content of $68.3 \%$ was obtained with a flavonoid recovery of $93.7 \%$ after purification. These results showed that the flavonoids were purified successfully with the higher content. In addition, flavonoids from corn silk had notable anti-hyperlipidemic activities by reducing the concentration of serum TC, TG and LDL-C, and increasing the concentration of HDL-C.

\section{ACKNOWLEDGEMENTS}

This work was supported by the Anhui Industry and Technology System of Poultry Science (AHCYTX-10), the Talent Stable Fund of AHAU, the Biology Key Subject Construction of Anhui, the SRF of AHAU (2005) and the Open Fund of State Key Laboratory of Animal Nutrition (2004DA125184F1418).

\section{Statement of conflict of interest}

Authors have declared no conflict of interest.

\section{REFERENCES}

Allain, C.C., Poon, L.S., Chan, C.S., Richmond, W.F.P.C. and Fu, P.C., 1974. Enzymatic determination of total serum cholesterol. Clin. Chem., 20: 470-475.

Biazus, J.P., Santana, J.C., Souza, R.R., Jordao, E. and Tambourgi, E.B., 2007. Continuous extraction of alpha- and beta-amylases from Zea mays malt in a PEG4000/CaCl2 ATPS. J. Chromatogr. B, 858: 227233. https://doi.org/10.1016/j.jchromb.2007.08.042

Biazus, J.P.M., Severo, J.B., Santana, J.C.C., Souza, R.R. and Tambourgi, E.B., 2006. Study of amylases recovery from maize malt by ionexchange expanded bed chromatography. Process Biochem., 41: 1786-1791. https://doi.org/10.1016/j. procbio.2006.03.025

Bibi, C., Khan, A., Shah, N., Raziq, S. and Yousafzai, A. M., 2016. Size dependent variation in cholesterol and fatty acids profile of different tissues of carnivore freshwater catfish, Wallago attu. Pakistan J. Zool., 48: 1017-1024.

Choi, S.Y.Y., Lee, S.S., Kim, H.M., Ju, J.H., Baek, C.S. and Lee, D.H., 2014. Inhibitory effect of corn silk on skin pigmentation. Molecules, 19: 2808-2818. https://doi.org/10.3390/molecules19032808

Ebrahimzadeh, M.A., Pourmorad, F. and Hafezi, S., 2008. Antioxidant activities of Iranian corn silk. Turk. J. Biol., 32: 43-49.

Feng, X., Wang, L., Tao, M.L., Zhou, Q. and Zhong, Z.H., 2012. Studies on antimicrobial activity of ethanolic extract of maize silk. Afr. J. Microbiol. Res., 2: 35-338. https://doi.org/10.5897/ajmr11.974

Fossati, P. and Prencipe, L., 1982. Serum triglycerides determined colorimetrically with an enzyme that produces hydrogen peroxide. Clin. Chem., 28: 2077-2080.

Fu, Y., Zu, Y.G., Efferth, T., Zhang, N.J., Liu, X.N. and Kong, Y., 2006. Optimization of luteolin separation from pigeonpea [Cajanus cajan (L.) Millsp.] leaves by macroporous resins. J. Chromatogr. A, 1137: 145152. https://doi.org/10.1016/j.chroma.2006.08.067

Hamza, R.G., Shahat, L.A.N. and Mekawey, H.M.S., 2013. Hypoglycemic and hypolipidemic effect of gamma-irradiated corn silk on male albino rats. Arab J. Nucl. Sci. App., 46: 252-259.

Hu, Q.L., Zhang, L.J., Li, Y.N., Ding, Y.J. and Li, F.L., 2010. Purification and anti-fatigue activity of flavonoids from corn silk. Int. J. Physiol. Sci., 5: 321-326.

Jing, Y., Jing, R.Q., Ren, Y. and Hu, T.H., 2010, Effects of flavones from Zea mays L. (ZMLF) on blood lipid and hemorheologic parameters in hyperlipemic 
rats. Chin. J. New Drug, 19: 797-800.

Jung, S., Lee, M.S., Shin, Y., Kim, C.T., Kim, I.H., Kim, Y.S. and Kim, Y., 2014. Anti-obesity and antiinflammatory effects of high hydrostatic pressure extracts of ginseng in high-fat diet induced obese rats. J. Funct. Fds., 10: 169-177. https://doi. org/10.1016/j.jff.2014.06.007

Kim, M.R., Kim, W.C., Lee, D.Y. and Kim, C.W., 2007. Recovery of narirutin by adsorption on a nonionic polar resin from a water-extract of Citrus unshiu peels. J. Fd. Eng., 78: 27-32. https://doi. org/10.1016/j.jfoodeng.2005.09.004

Kim, S.G., Choi, J.W., Park, H.J., Lee, S.M. and Jung, H.J., 2009. Anti-hyperlipidemic effects of the flavonoid-rich fraction from the methanol extract of orostachy japonicus in rats. Korean J. Pharmacog., 40: 51-58.

Li, H., Liu, J., Li, D. and Wang, H.K., 2011. Study on separation and purification of Geniste in the soybean residue using macroporous resin adsorption. Ind. Eng. Chem. Res., 51: 44-49.

Liu, J., Wang, C.N., Wang, Z.Z., Zhang, C., Lu, S. and Liu, J.B., 2011. The antioxidant and free-radical scavenging activities of extract and fractions from corn silk (Zea mays L.) and related flavone glycosides. Fd. Chem., 126: 261-269. https://doi. org/10.1016/j.foodchem.2010.11.014

Liu, X.M., Xiao, G.S., Chen, W.D., Xu, Y.J. and Wu, J.J., 2004. Quantification and purification of mulberry anthocyanins with macroporous resins. BioMed. Res. Int., 5: 326-331. https://doi.org/10.1155/ s1110724304403052

Qin, X. and Jin, X.Y., 2014. Studies on purification of platycodins by AB-8 macroreticular resin. J. Chem. Pharm. Res., 6: 388-392.

Rostagno, M.A., Palma, M. and Barroso, C.G., 2003.
Ultrasound-assisted extraction of soy isoflavones. J. Chromatogr. A, 12: 119-128. https://doi. org/10.1016/S0021-9673(03)01184-1

Smith, N.W. and Evans, M.B., 1995. The efficient analysis of neutral and highly polar pharmaceutical compounds using reversed-phase and ion-exchange electrochromatography. Chromatographia, 41: 197-203. https://doi.org/10.1007/BF02267955

Wan, P.F., Sheng, Z.L., Han, Q., Zhao, Y.L., Cheng, G.D. and Li, Y.H., 2014. Enrichment and purification of total flavonoids from Flos populi extracts with macroporous resins and evaluation of antioxidant activities in vitro. J. Chromatogr. B, 945: 68-74. https://doi.org/10.1016/j.jchromb.2013.11.033

Weggemans, R.M. and Trautwein, E.A., 2003. Relation between soy-associated isoflavones and LDL and cholesterol concentrations in humans: a metaanalysis. Eur. J. clin. Nutr., 57: 940-946. https:// doi.org/10.1038/sj.ejcn.1601628

Zhang, E.J., Ng, K.M. and Luo, K.Q., 2007. Extraction and purification of isoflavones from soybeans and characterization of their estrogenic activities. J. Agric. Fd. Chem., 55: 6940-6950. https://doi. org/10.1021/jf0708903

Zhao, W.Z., Yin, Y.G., Yu, Z.P., Liu, J.B. and Chen, F., 2012. Comparison of anti-diabetic effects of polysaccharides from corn silk on normal and hyperglycemia rats. Int. J. Biol. Macromol., 50: 1133-1137. https://doi.org/10.1016/j. ijbiomac.2012.02.004

Zhao, Z.Y., Dong, L.L., Wu, Y.L. and Lin, F., 2011. Preliminary separation and purification of rutin and quercetin from Euonymus alatus (Thunb.) Siebold extracts by macroporous resins. Fd. Bioprod. Process, 89: 266-272. https://doi.org/10.1016/j. fbp.2010.11.001 